\title{
The Effect of Task, Organizational, and Family Factors on Taking Parental Leave: Gender Differences among Employees
}

\author{
Yutaka Ueda (Corresponding author) \\ Faculty of Economics, Seikei University \\ 3-3-1, Kichijoji-kitamachi, Musashino, Tokyo, Japan \\ Tel: 81-422-373-589 E-mail: ueda@econ.seikei.ac.jp
}

Kana Kurosawa

Graduate School of Economics and Management, Seikei University

3-3-1, Kichijoji-kitamachi, Musashino, Tokyo, Japan

Received: April 25, 2012

Accepted: May 28, 2012

Online Published: June 15, 2012

doi:10.5430/bmr.v1n2p113

URL: http://dx.doi.org/10.5430/bmr.v1n2p113

\begin{abstract}
Parental leave is one of most important policies for employees in nations like Japan that suffer from a low birthrate. Despite the various plans implemented by the Japanese government, fathers take significantly less parental leave than mothers. In the Japanese culture, which emphasizes gender role differentiation, male employees have a greater fear of providing unfavorable signals to employers regarding their dedication and performance if they take parental leave than female employees do. The present research examined data from 1553 Japanese employees, revealing that individual work and family factors influence the behaviors of female employees but not those of male employees. However, the perception of organizational support, which reduces employees' fear of giving employers the wrong impression when taking parental leave, has an impact on both male and female employees.
\end{abstract}

Keywords: Parental leave, Work-life balance, Japanese employees

\section{Introduction}

Currently, the low birthrate is one of the most serious problems affecting Japan. Although the Japanese government has introduced various plans and laws to improve work-life balance (WLB) and increase the birthrate, such as "Angel Plan" (1994), "New Angel Plan" (1999), "Plus One" (2002), and "Act for Measures to Support the Development of the Next Generation" (2003), the total fertility rate (TFR) dropped from 1.42 in 1995 to a record low of 1.26 in 2005. This declining birthrate implies that the measures and actions taken by the government are not necessarily sufficient to encourage Japanese employees to improve WLB and increase the birthrate. For example, as one of the data showing insufficiency of government plans, the survey that was conducted by The Ministry of Health, Labour, and Welfare (MHLW) in 2009 revealed that $75.6 \%$ of the Japanese respondents gave low evaluations to the Japanese government's countermeasures to the falling birthrate (White Paper on Society with Fewer Children, 2009).

Therefore, it is also important to consider the effect that other employee factors may have on the low birthrate in Japan. In particular, we are concerned with the use of parental leave as one of the measures intended to increase the birthrate. Parental leave (sometimes referred to as childcare leave) is defined as temporally leaving work to care for children and has been recognized as an important factor in encouraging employees to bear and raise children. Facilitation of parental leave has become one of the critical problems in improving child health (Garfield, Pickett, Chung, \& Lantos, 2003; Ruhm, 2000; Schuster et al., 2009) and parents' own mental health (Feldman, Sussman, \& Zigler, 2004).

Japan's Child Care and Family Care Leave Law guarantees that all employees, regardless of gender, who have worked for the organization for over a year and who expect to continue to work (after parental leave) have the right to temporary leave for childcare. However, according to another survey by MHLW in 2010, the rates of those taking parental leave were $83.7 \%$ for women but only 1.38\% for men (General Survey of Equal Employment Opportunity, 2010). Although rates of those taking parental leave in other countries also vary according to gender (Engstrom, Kolm, \& Liang, 2009), the differences in rates were generally not as striking (Garfield et al., 2003; Sorlin, Ohman, 
Blomstedt, Stenlund, \& Lindholm, 2011).

The differences between male and female employees taking parental leave indicate that different factors linked to gender are likely to influence childcare decisions, even if both male and female employees have equal legal rights to parental leave within their organizations.

In this article, we focus on employees' fear of giving employers the wrong impression as a result of taking parental leave. We specifically assume that this effect is stronger for men than for women because of culturally embedded gender differentiation. Our empirical study examines whether factors associated with the fear of being judged as an inferior or disloyal employee inhibit male and female workers from taking parental leave. The findings of this article are expected to inform processes that will enable the development of more realistic organizational plans that encourage both male and female employees to participate in childcare and to take parental leave. In particular, findings of specific factors that inhibit male employees from taking parental leave may be important for improving the rates at which they currently take parental leave.

\section{Japanese Culture and Fear of Being Regarded as an Inferior Employee}

Currently, many countries have laws covering employee parental leave. In Japan, the Act on the Welfare of Workers Who Take Care of Children or Other Family Members Including Child Care and Family Care Leave was initially established in 1991. The current version of this Act, implemented in 2010, attempts to further encourage male employees to take parental leave by guaranteeing their right, regardless of spousal employment, to do so. Although it is said that the legal system regarding parental leave in Japan is still behind the systems in countries such as Sweden and Finland, which have more advanced welfare systems (Oh, 2008), we cannot attribute the low rate of Japanese male parental leave solely to a defect in the country's legal system. In addition to the legal system, we must focus on perceived differences in the roles of men and women embedded in Japanese culture (Hatayama, 2010; Fujishima, 2010).

Watts (2009) observed that presenteeism culture, which suggests that ideal employees should have unlimited time available to spend at work, increases work-family conflict; such a culture requires employees stay late at the office to show their commitment and loyalty to the organization, even if they have no concrete work to do. Watts (2009) noted, "(t)he way that work 'flexibility' was used implied, in the main, an availability and willingness to stay at work as long as necessary and those who could not conform to this expectation were regarded as less loyal and certainly less committed" (pp. 45-46). Further, Amilton (2010) showed that single mothers in Sweden took less temporary parental leave, which Amilton attributed to mothers' fear that employers would have an unfavorable impression of those who took leave. Employers are likely to want employees who stay at work and prefer employees who do not take parental leave. Coleman and Franiuk (2011) also revealed parents who took parental leave were perceived as less successful in their career than working parents. If employers are aware of employees taking parental leave, they are less likely to give those employees crucial responsibilities and are less likely to promote them. Further, if employees fear they are giving their employers the wrong impression of their dedication, they will regard parental leave less positively than those who do not have such a fear.

Although Watts (2009) and Amilton (2010) explained their ideas with reference to working conditions in European countries, such as the UK and Sweden, their work can also effectively interpret workplaces in Japan for the following two reasons: First, the boundaries of formal roles in Japan are more often seen as ambiguous than those in the West (Yoshimura \& Anderson, 1997), and most Japanese organizations have only vague or pro forma job descriptions. If employees do not have clear job descriptions to follow, they can easily feel uncertain about what to do to receive recognition in the organization, and they are more afraid that their behavior may unintentionally provide the wrong impression to employers. Second, Japanese employers encourage peer relationships and shared activities among their employees because, as members of a collectivist culture, they strongly believe shared experiences facilitate mutual understanding between employees. Being present at the office is one of the important requirements placed on Japanese workers, so that they will be able to identify with each other as a team.

Further, in the Japanese workplace, this working condition is considered to have a different effect on male and female employees. Yamanishi (2008) compared nurturing attitudes among five countries-Korea, the US, France, Sweden, and Japan - and found that Japanese people more strongly believed that "a wife should bring up the family while a husband should work outside" than people in all other four countries. Yamanishi concluded that the Japanese had an especially strong sense of gender role differentiation, which influenced the work behaviors of both men and women. Japanese employers are considered to place stronger demands on their male-as opposed to female - employees to be at the office. In other words, Japanese male employees experience more pressure to stay at the office than female employees do. 


\section{Hypotheses}

As described in the previous section, the pressure of traditional presenteeism culture to stay at work is assumed generally to be stronger for male employees rather than female employees. Consequently, unless male employees perceive that they will not be unfavorably judged at workplace, they will be unlikely to take parental leave. In other words, although the workers' own work and family conditions generally influence their decision to take parental leave, work and family conditions alone do not influence the men's decision to take leave. Rather male employees must feel that the organization genuinely supports their use of parental leave. In the present study, the degree of overtime and status as the primary earner in the family are treated as the employees' own work and family conditions, respectively. Moreover, employees' perception of organizational WLB orientation is treated as their evaluation of organizational supportiveness of the employees. The concrete hypotheses are explained as follows:

First, one of the simplest work conditions is the pressure or business of work. If employees are busy or feel pressured to work, they will experience difficulty in taking parental leave. Hammig, Gutzwiller, and Bauer (2009), using the data of those living and working in Switzerland, found that working hours and regular overtime increased work-life conflict for both male and female employees. Hang (2011) also explained work time as one of the factors inhibiting the improvement of WLB in Japan. However, even if male employees do not work overtime, they strongly regard staying at work as an obligation and a necessity for being seen as competent and loyal. Therefore, the degree of overtime will be influential in parental leave decisions for female employees, but not for male employees. We therefore propose the following Hypothesis $1(\mathrm{H} 1)$ :

H1: Overtime will negatively influence the use of parental leave for female employees but not for male employees.

Second, status as the primary earner in the family is considered a family condition in this paper. Ogawa (2010) described the factors inhibiting men's use of parental leave as follows, "[P]robably the economic ramifications are the biggest inhibitor for men when it comes to using parental leave. If a husband takes parental leave, his family will be hurt because husbands still support the family financially in most cases" (p. 195, translated in English by author). If Ogawa is right, the husband will be more likely to take leave when his wife, or other family members, earn sufficient money to support the family. In fact, Naz (2010) showed that mothers' relative income was one of the most important factors for the use of gender-neutral leave by fathers in Norway.

However, Ogawa's descriptions, although interesting, are based largely on the current husband's position in the family. In other words, Ogawa ignored the gender role differentiation in the workplace. Even if male employees are not the primary earners in the family, if they live in a society where they are required to work at office, then they will still want to stay at work because they will be worried about being considered inferior employees. Accordingly, we propose Hypothesis 2 (H2):

$\mathrm{H} 2$ : Employees who make the most money in their family will take parental leave less often than other employees if they are female but not if they are male.

If these individual work and family conditions do not influence male employees' use of parental leave, then what kinds of factors should be considered instead? The degree to which male employees fear that their employers construe the use of parental leave negatively is not always the same and depends on the organization's rules and culture. If employees perceive that their organizations positively support their WLB, they will be less afraid of making the wrong impression on their employers when taking leave. Tremblay and Genin (2010) also indicated the importance of making employees feel supported in taking parental leave; the effect of an employee's perception is relatively pervasive regardless of gender. In other words, with regard to this effect on the use of parental leave, there appears to be no gender difference. This consideration gives rise to Hypothesis 3 (H3):

H3: Employees who perceive that an organization's orientation to WLB is positive will take parental leave more frequently than employees who do not, regardless of gender.

\section{Research Methods}

\subsection{Data and Sample}

The present data are from the "Survey of Support for the Balancing of Work and Family in Future Years" conducted by the NLI Research Institute in 2007 under the order of the Ministry of Health, Labour and Welfare. The NLI Research Institute provided the University of Tokyo the opportunity to use the data. Initially, NLI randomly selected 4,000 companies that had 10 or more employees, based on Teikoku Databank's database of Japanese companies and subsequently it distributed 2 to 7 questionnaires to employees in each of the companies, according to company size. As a result, 12,000 questionnaires were distributed to regular employees aged 40 or under, and the number of valid 
responses was 1,553 (valid response rate was $12.9 \%$ ). Of these 1,553 employees, 752 were male and 801 were female.

\subsection{Measures}

Some variables from the data were utilized with no modification, whereas other variables were processed according to our hypotheses.

Overtime: The amount of overtime was measured by one item with a three-point range from "no overtime" to "some overtime" to "constant overtime." We used this variable without alteration because we were not sure how "some overtime" influences the use of parental leave.

The primary earner in the family: The respondents were asked to choose the person who earned the most money in their household from the following three options: themselves, their spouse, or others. We combined the respondents who answered that their spouses or others were the primary earners and then divided all the respondents into two categories: "themselves" or "spouse or others."

Perception of organization's attitude toward support of employee WLB: This was measured with a four-point scale item from [1] "negative" to [4] "positive."

Gender: Employee gender was quantified as either [1] male or [2] female.

\section{Results}

Table 1 shows the difference between the number (and percentages) of employees who took parental leave and other employees who did not take parental leave by gender. Similar to the data from the government survey already described in the first section, a relatively high proportion of female employees took parental leave, whereas only 15 of 752 male employees took such leave. The infrequency at which male employees took parental leave makes it difficult to employ rigorous statistical analysis to focus on the reason why they did or not take parental leave. We, therefore, conducted simple cross tabulations to get a brief glimpse at the tendency to take parental leave by gender.

\section{Insert Table 1 Here}

According to Hypothesis 1 (H1), overtime will have a negative effect on parental leave for female employees, but not for male employees. Table 2 depicts the cross table of the degree of overtime and parental leave by gender. Frequency (Freq.), expected frequency (Exp. Freq.), and percentage (Perc.) of each cell in the table are shown in Table 2 (and other tables in this section). The chi square and the difference between the actual and expected frequencies indicate that the effect of overtime on parental leave is found in the female sample, but not in the male sample. In other words, male employees always find it difficult to take parental leave regardless of how busy they are. Therefore, $\mathrm{H} 1$ is supported.

\section{Insert Table 2 Here}

$\mathrm{H} 2$ assumed that female employees who are the primary earners in their family would take parental leave less often than other employees. This relationship was not expected for the male sample because male employees are more afraid of negative signaling. In Table 3, the cross table of maximum earner and parental leave shows that female employees who are the primary earners in the family take parental leave significantly less often than females who are not. This relationship is not seen in male employees. Therefore, $\mathrm{H} 2$ is also supported.

\section{Insert Table 3 Here}

Table 4 shows employee perception of an organization's positive orientation toward WLB and parental leave. According to H3, employees will take parental leave more often when they perceive that their organization adopts a favorable attitude toward employee WLB than when they do not. Table 4 reveals this effect for both male and female employees. Therefore, $\mathrm{H} 3$ is supported.

\section{Discussion and Conclusion}

This article examined whether various factors influencing the use of parental leave differed by gender. As hypothesized, the present empirical research revealed that male employees decided to take parental leave not because of individual work and family conditions, but because of their perception of an organization's level of support for parental leave, which is considered to have an impact on employees' concerns whether their taking leave gave the impression of disloyalty and incompetence.

All the proposed hypotheses were supported in this study; these results demonstrate the importance of organizations 
ensuring that employees perceive employers as supportive of parental leave. This might be more difficult to accomplish in Japanese cultural than would seem. For example, simply implementing various WLB programs, including parental leave, and informing employees of their availability might not be enough to make Japanese employees believe that the organizations have a favorable view of WLB. Japanese society strongly differentiates between Honne and Tatemae, that is, one's real intention and what one says on the surface (David, 1997; Doyon, 2001; Fetters, 1995; Herbig \& Jacobs, 1998; Martin, 2012; Shwalb, Kawai, Shoji, \& Tsunetsugu, 1997). The formal system of an organization belongs to Tatemae. As a result, even if male employees know that an organization's formal system encourages parental leave, they may nonetheless infer that the organization's Honne contrasts with the formal system. Ultimately, the employees may hesitate to take parental leave because they recognize that Honne always takes precedence over Tatemae in Japanese society. Focusing on the knowledge of the formal aspect of WLB programs alone therefore might not reveal how employees contend with Honne and Tatemae in the context of parental leave. Japanese organizations must convince their employees that they highly value their employees' WLB as Honne.

This article has some limitations that should be addressed in future studies. First, simple cross tabulations were largely adopted because of the constraints of the available data. However, causal relationships cannot be rigorously investigated by such simple cross tabulations. For example, we assumed that employee perceptions of the organizational WLB orientation would influence the use of parental leave, and simple cross tabulation shows that these two factors are related. However, this table cannot specify the causal relationship between these two factors as hypothesized. In addition, it must be considered that the employees' experience of taking parental leave may have caused them to evaluate their organization's WLB orientation positively. Second, for those males who do not take parental leave, the present research did not distinguish between male employees who would take leave if they could and those who do not take it, even though it is offered. Although simply asking whether they hope to take parental leave seems like one possible solution, it might not resolve this problem because it does not capture the reasoning behind the final decision. For example, male employees might refuse to take leave not only when they think that taking parental leave will prevent them from being promoted but also when they believe that the WLB approach of the organization is weak and unhelpful to them.

Despite these limitations, this article sheds light on the factors that influence the use of parental leave, especially the similarities and differences between the genders. We hope the findings of this article will prompt researchers to look at the factors facilitating or inhibiting men's use of parental leave and their WLB.

\section{References}

Amilton, A. (2010). The temporary leave dilemma: Lone and partnered mothers in Sweden, Feminist Economics, 16(4), 33-52. http://dx.doi.org/10.1080/13545701.2010.530604

Cabinet Office. (2009). Internet survey of image of low birthrate society (in Japanese), http://www8.cao.go.jp/shoushi/cyousa/cyousa21/net-image/g-mokuji-pdf.html

Coleman, J. M., \& Franiuk, R. (2011). Perceptions of mothers and fathers who take temporary work leave, Sex Roles, 64(5), 311-323. http://dx.doi.org/10.1007/s11199-010-9918-8

Doyon, P. (2001). A review of higher education reform in modern Japan, Higher Education, 41, 443-470. Stable URL: http://www.jstor.org/stable/3448133

Engstrom, P., Kolm, A. S., \& Liang, C. Y. (2009). Maternal-biased parental leave, Journal of Economic Psychology, 30(4), 583-590. http://dx.doi.org/10.1016/j.joep.2009.04.002

Feldman, R., Sussman, A. L., \& Zigler, E. (2004). Parental leave and work adaptation at the transition to parenthood: Individual, marital, and social correlates, Applied Developmental Psychology, 25(4), 459-479. http://dx.doi.org/10.1016/j.appdev.2004.06.004

Fetters, M. D. (1995). Nemawashi essential for conducting research in Japan, Social Science \& Medicine, 41(3), 375-381.

Fujishima, K. (2010). Relationship between facilitators of work-life balance and utility of corporations (in Japanese), Annual Convention, Japanese Association of Administrative Science, 13, 385-388.

Garfield, C. F., Pickett, K. E., Chung, P. J., \& Lantos, J. (2003). Ambulatory Pediatrics, 3(5), 228-233.

Hammig, O., Gutzwiller, F., \& Bauer, G. (2009). Work-life conflict and associations with work- and nonwork-related factors and with physical and mental health outcomes: A nationally representative cross-sectional study in Switzerland, BMC Public Health, 9, 435-449. 
Hang, S. (2011). Analysis of work-life balance of institution as occupational welfare: An examination of the theoretical framework (in Japanese), Yokohama Journal of Social Sciences, 15(6), 755-774.

Hatayama, M. (2010). Problems to support plans for childcare as principal measures to protect against declining birthrate (in Japanese), Journal of Developmental Science Miyagi Gakuin Women's College, 10, 63-67.

Herbig, P., \& Jacobs, L. (1998). Culture as an explanatory variable for the Japanese innovative processes, Cross Cultural Management: An International Journal, 5(3), 5-30.

Martin, D. (2012). Foreign women in Japanese television advertising content analyses of a cultural convergence paradigm, European Journal of Marketing, 46(1/2), 157-176. http://dx.doi.org/10.1108/03090561211189275

Naz, G. (2010). Usage of parental leave by fathers in Norway, International Journal of Sociology and Social Policy, 30(5/6), 313-325. http://dx.doi.org/10.1108/01443331011054262

Ogawa, S. (2010). Work-life balance policy: The ratio of male and female workers who use the childcare leave system (in Japanese), Educational Inquiry, 54, 185-198.

Oh, J. (2008). Family policy in Japan, Sweden, Finland, Netherland, and Belgium (in Japanese), Bulletin of Daito Bunka University, 46, A237-A248.

Ruthm, C. J. (2000). Parental leave and child health, Journal of Health Economics, 19(6), 931-960. http://dx.doi.org/10.1016/S0167-6296(00)00047-3

Schuster, M. A., Chung, P. J., Elliott, M. N., Garfield, C. F., Vestal, K. D., \& Klein, D. J. (2009). Perceived effects of leave from work and the role of paid leave among parents of children with special health care needs, American Journal of Public Health, 99(4), 698-705. http://dx.doi.org/10.2105/AJPH.2008.138313

Shwalb, D. W., Kawai, H., Shoji, J., \& Tsunetsugu, K. (1997). The middle class Japanese father: A survey of parents of preschoolers, Journal of Applied Developmental Psychology, 18, 497-511.

Sorlin, A., Ohman, A., Blomstedt, Y., Stenlund, H., \& Lindholm, L. (2011). Measuring the gender gap in organizations, Gender in Management: An International Journal, 26(4), 275-288. http://dx.doi.org/10.1108/17542411111144292

Tremblay, D. G., \& Genin, E. (2010). Parental leave: From perception to first-hand experience, International Journal of Sociology, 30(9/10), 532-544. http://dx.doi.org/10.1108/01443331011072280

Watts, J. H. (2009). 'Allowed into man's world' meaning of work-life balance: Perspectives of women civil engineers as 'minority' employees in construction, Gender, Work, and Organization, 16(1), 37-57. http://dx.doi.org/10.1111/j.1468-0432.2007.00352.x

Yamanishi, H. (2008). The shift in family policy from combining work with having a family to supporting the family work-life balance: The problem with child caring support policy (in Japanese), Journal of Kyushu University of Health and Welfare, 9, 53-62.

Yoshimura, N., \& Anderson, P. (1997). Inside the Kaisha: Demystifying Japanese Business Behavior, Harvard Business School Press.

Table 1. Gender and Experience of Parental Leave

\begin{tabular}{|ll|c|c|c|}
\hline & & \multicolumn{2}{|l|}{ Parental Leave } & \multirow{2}{*}{ Total } \\
\cline { 3 - 4 } & & Not Taken & Taken & \\
\hline Gender & Male & $737(47.5 \%)$ & $15(1.0 \%)$ & $752(48.4 \%)$ \\
& Female & $439(28.3 \%)$ & $362(23.3 \%)$ & $801(51.6 \%)$ \\
Total & $1,176(75.7 \%)$ & $377(24.3 \%)$ & $1,553(100.0 \%)$ \\
\hline
\end{tabular}


Table 2. Overtime and Parental Leave

\begin{tabular}{|c|c|c|c|c|c|c|c|c|}
\hline & \multicolumn{2}{|c|}{$\begin{array}{l}\text { Parental Leave } \\
\text { (Male) }\end{array}$} & \multirow[t]{2}{*}{ Total } & \multicolumn{2}{|c|}{$\begin{array}{c}\text { Parental Leave } \\
\text { (Female) }\end{array}$} & \multirow[t]{2}{*}{ Total } \\
\hline & & & Not Taken & Taken & & Not Taken & Taken & \\
\hline \multirow{10}{*}{ Overtime } & & Freq. & 404 & 9 & 413 & 88 & 46 & 134 \\
\hline & Constant & Exp. & 404.8 & 8.2 & 413.0 & 73.5 & 60.5 & 134.0 \\
\hline & & $\begin{array}{l}\text { Iich. } \\
\text { Perc. }\end{array}$ & $53.7 \%$ & $1.2 \%$ & $54.9 \%$ & $11.0 \%$ & $5.8 \%$ & \\
\hline & Some & Freq. & 269 & 6 & 275 & 195 & 155 & 350 \\
\hline & Overtime & Exp. & 269.5 & 5.5 & 275.0 & 192.1 & 157.9 & 350.0 \\
\hline & & Perc. & $35.8 \%$ & $0.8 \%$ & $36.6 \%$ & $24.4 \%$ & $19.4 \%$ & \\
\hline & & Freq. & 64 & 0 & 64 & 156 & 160 & 316 \\
\hline & Overtime & Exp. & 62.7 & 1.3 & 64.0 & 173.4 & 142.6 & 316.0 \\
\hline & & Freq. & & & & & & \\
\hline & & Perc. & $8.5 \%$ & $0.0 \%$ & $8.5 \%$ & $19.5 \%$ & $20.0 \%$ & $39.5 \%$ \\
\hline \multicolumn{2}{|l|}{ Total } & Freq. & 737 & 15 & 752 & 439 & 361 & 800 \\
\hline
\end{tabular}

Table 3. Primary Earner and Parental Leave

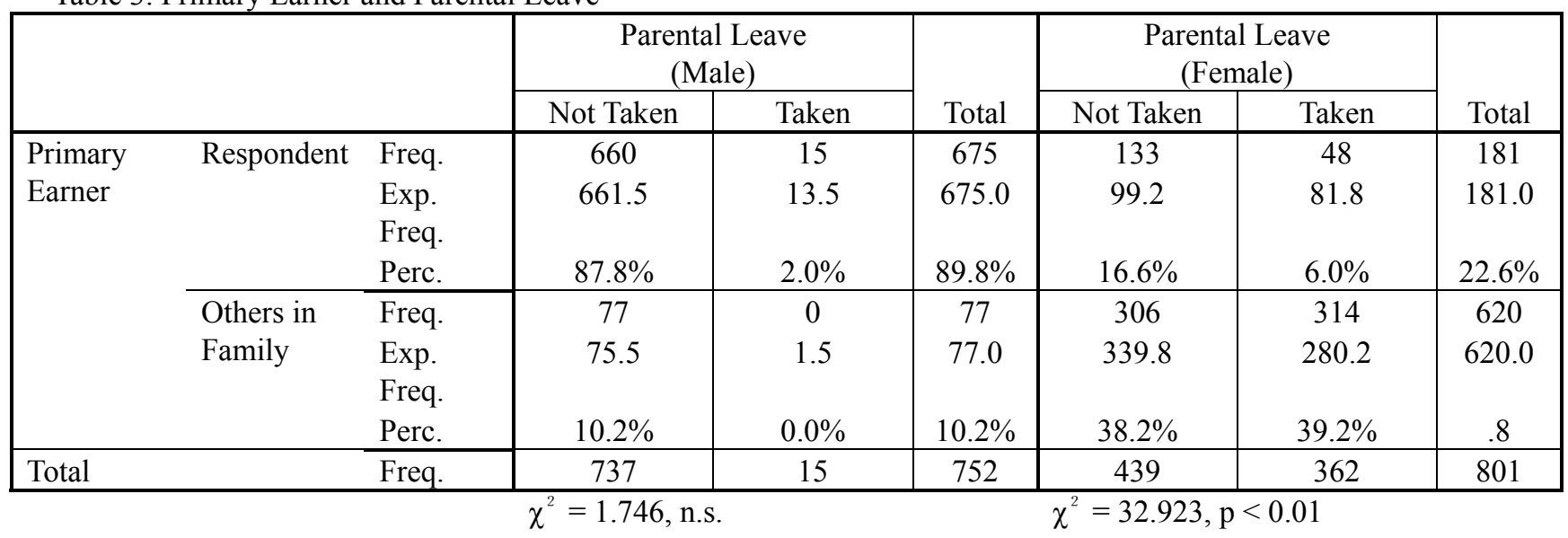

Table 4. Perception of Organizational WLB Orientation and Parental Leave

\begin{tabular}{|c|c|c|c|c|c|c|c|c|}
\hline & \multicolumn{2}{|c|}{$\begin{array}{c}\text { Parental Leave } \\
\text { (Male) }\end{array}$} & \multirow[b]{2}{*}{ Total } & \multicolumn{2}{|c|}{$\begin{array}{c}\text { Parental Leave } \\
\text { (Female) }\end{array}$} & \multirow[b]{2}{*}{ Total } \\
\hline & & & Not Taken & Taken & & Not Taken & Taken & \\
\hline \multirow{6}{*}{$\begin{array}{l}\text { Perception of } \\
\text { Organizationa } \\
1 \text { WLB } \\
\text { Orientation }\end{array}$} & Positive & Freq. & 285 & 11 & 296 & 233 & 222 & 455 \\
\hline & & $\begin{array}{l}\text { Exp. } \\
\text { Freq. }\end{array}$ & 290.1 & 5.9 & 296.0 & 249.4 & 205.6 & 455.0 \\
\hline & & Perc. & $37.9 \%$ & $1.5 \%$ & $\begin{array}{c}39.4 \\
\%\end{array}$ & $29.1 \%$ & $27.7 \%$ & $\begin{array}{l}56.8 \\
\%\end{array}$ \\
\hline & Negative & Freq. & 452 & 4 & 456 & 206 & 140 & 346 \\
\hline & & $\begin{array}{l}\text { Exp. } \\
\text { Freq. }\end{array}$ & 446.9 & 9.1 & 456.0 & 189.6 & 156.4 & 346.0 \\
\hline & & Perc. & $60.1 \%$ & $0.5 \%$ & $\begin{array}{c}60.6 \\
\% \\
\end{array}$ & $25.7 \%$ & $17.5 \%$ & $\begin{array}{l}43.2 \\
\% \\
\end{array}$ \\
\hline \multicolumn{2}{|l|}{ Total } & Freq. & 737 & 15 & 752 & 439 & 362 & 801 \\
\hline
\end{tabular}

